\title{
Stunting-Related Knowledge: Exploring Sources of and Factors Associated with Accessing Stunting-Related Knowledge among Mothers in Rural Indonesia
}

\author{
Joshua West ${ }^{1 *}$, Ahmad Syafiq ${ }^{2}$, Benjamin Crookston'1, Cudjoe Bennett ${ }^{3}$, Muhamad R. Hasan", \\ Kirk Dearden', Mary Linehan ${ }^{3}$, Cougar Hall ${ }^{1}$, Scott Torres ${ }^{3}$ \\ ${ }^{1}$ Department of Public Health, Brigham Young University, Provo, UT, USA \\ ${ }^{2}$ Faculty of Public Health, Universitas Indonesia, Depok, Indonesia \\ ${ }^{3}$ IMA World Health, Washington DC, USA \\ ${ }^{4}$ IMA World Health, Jakarta, Indonesia \\ ${ }^{5}$ IMA World Health, Dar es Salaam, Tanzania \\ Email: *josh.west@byu.edu
}

How to cite this paper: West, J., Syafiq, A., Crookston, B., Bennett, C., Hasan, M.R., Dearden, K., Linehan, M., Hall, C. and Torres, S. (2018) Stunting-Related Knowledge: Exploring Sources of and Factors Associated with Accessing Stunting-Related Knowledge among Mothers in Rural Indonesia. Health, 10, 1250-1260.

https://doi.org/10.4236/health.2018.109096

Received: August 1, 2018

Accepted: September 23, 2018

Published: September 26, 2018

Copyright $\odot 2018$ by authors and Scientific Research Publishing Inc. This work is licensed under the Creative Commons Attribution International License (CC BY 4.0).

http://creativecommons.org/licenses/by/4.0/

\begin{abstract}
Background: Stunting in young children continues to be a major concern in developing country settings, including middle income countries like Indonesia. Early intervention is critical to prevent increased morbidity and mortality, lower cognitive functioning, and diminished productivity in adulthood. Mothers may benefit from knowledge and information related to stunting causes and effects. Indonesia has readily adopted a variety of platforms, which are now being used to disseminate health information. The purpose of this study was to address two related research questions: 1 ) What are the primary sources of Indonesian mothers' stunting-related knowledge? 2) What factors are associated with using these various platforms to access stunting-related information? Method: Mothers $(\mathrm{n}=745)$ responded to questions about demographics and the source of stunting knowledge, which included hospitals, the Internet, midwives, posyandu (community health posts), and puskesmas (public health centers). Multivariate logistic regression was used to identify factors associated with mothers' reported use of the three most common sources to acquire information about stunting, including posyandu, puskesmas and the Internet. Results: Eighty percent of mothers in this study sample used posyandu, $31.7 \%$ puskesmas, and $16.9 \%$ used the Internet as a source for stunting-related knowledge. For the three most common sources, factors associated with each included not accessing the other sources. Conclusions: Indonesian mothers are using a variety of platforms and services to acquire
\end{abstract}


information about stunting. These sources are different one from another and each may be an important resource for disseminating health information, especially outside of urban centers. Results from this study may help to identify characteristics of Indonesian mothers who could benefit from acquiring stunting-related information in these formats. Each of these sources of information appears to be utilized by different groups of mothers. This is an important finding as it suggests that each may continue to be a resource for mothers that might not otherwise access stunting information. The Indonesian health system in rural settings has a history of support for posyandu and puskesmas. Moving forward, the Internet may also be used to improve outcomes for children of mothers that do not access information through these more traditional means.

\section{Keywords}

Indonesia, Internet, Nutrition Knowledge, Posyandu, Puskesmas, Stunting

\section{Introduction}

Worldwide, 171 million children (167 million in developing countries) have growth stunting, which is defined as height-for-age $\mathrm{z}$ score (HAZ) [1] 2 standard deviations below the reference for their age and sex [2]. In Indonesia, the prevalence of stunting among children under 5 is 37.2 percent, and stunting ranges from 23 percent to 58 percent [3]. Stunting is associated with feeding practices including frequency, amount, consistency, and variety of foods, along with whether feeding is responsive to children's needs; frequency of infections due to poor hygiene and lack of access to improved sanitation; and inadequate psychosocial stimulation [4]. Stunting may result in increased morbidity and premature mortality, delayed motor development, lower cognitive functioning and school achievement, as well as decreased worker productivity [4].

Efforts to increase maternal stunting-related knowledge may be an effective approach for addressing and preventing stunting. Examples of knowledge could include being more aware of healthy feeding practices [5], knowledge of nutrient diversity among various available food options [6], being able to correctly identify stunting and nutritional status more broadly [7], and childcare practices [8].

The exact method for disseminating this knowledge may depend on the locally available resources, both provider and patient preferences and a variety of other factors. Nevertheless, there are likely a variety of platforms being used. For example, research with mothers in western settings has shown a shifting preference for acquiring child feeding information, away from professionals and toward digital or social forms, such as television or friends [9] [10]. These shifts mirror larger trends of health seeking behaviors, which are gravitating toward internet sources [11]. Even in some developing country settings, there is a growing need and opportunity among mothers for accessing health-related in- 
formation from online sources [12]. While much of Indonesia remains rural, an emerging economy, growing infrastructure, and increased accessibility to the Internet, present opportunities for the online dissemination of health-related information. To date, however, little is known about the sources of stunting-related knowledge among Indonesian mothers. In particular, no study has explored these sources of stunting knowledge and the factors associated with their use. The purpose of this study was to explore current sources of stunting-related knowledge and gain insight into factors which may be associated with their use to seek stunting-related information. Specifically, this study aims to answer two research questions: 1) What are the primary sources of stunting-related knowledge among Indonesian mothers? and 2) What factors are associated with using these sources to access stunting-related information among Indonesian mothers?

\section{Methods}

\subsection{Design}

The current investigation used data from a larger study designed to assess the impact and influence of nutrition-related attitudes and behaviors of mothers in rural Indonesian provinces. Data were collected to inform the development of a country-wide media campaign targeting childhood nutrition. The current study includes cross-sectional data collected prior to the mass media campaign.

\subsection{Sample/Setting}

The study sample consisted of 745 expecting mothers and mothers of children under two years of age. Respondents who did not qualify for one of these two categories were excluded. Women were recruited from five regions in Indonesia, including Sumatera, Java, Kalimantan, Nusa Tenggara and Sulawesi. These regions were selected because of the high prevalence of stunting and accessibility. The number of respondents within each region was determined using the World Health Organization's 30 Cluster Method [13]. A village within a district was considered a cluster, and seven were selected from each district. Respondents within clusters were then randomly selected to participate. The current study sample consisted of 745 participants. Data were collected from September to October, 2014

\subsection{Procedure}

The Universitas Indonesia human subjects review board approved this study's methods and procedures. Participants were recruited to participate in a 60-minute interview. After a participant's home was randomly selected for participation, an interviewer traveled to the home, acquired consent to participate and to publish the study's findings and then conducted a face-to-face interview. Participation rate was $100 \%$. Participants received a small collection of toiletry items for participating, including soap, a toothbrush, and toothpaste. Interview- 
ers used a structured interview guide to ask questions and collect responses. Participants' responses were recorded on the actual interview guide and were later transferred to an electronic database for data cleaning and analyses.

\subsection{Measurement}

Interviewers collected data from participating mothers regarding demographics, sources of stunting-related information, and at which point during pregnancy stunting-related information was accessed. Demographic variables related to education were measured by asking respondents to report their highest level of education attained. Fixed response categories included, "never studied" through "university post graduate". To aid analysis, this variable was recoded into four categories, less than or equal to elementary school education, some junior high or junior graduate, some high school or high school graduate, and some college or college graduate. Demographic variables related to socioeconomic status were assessed by a single measure of familial wealth used to represent home-based assets. This variable was created by summing respondents' reports that they owned any of the following assets (yes/no): radio, hand phone, refrigerator, television, bicycle/boat, motorcycle/motorbike, and computer/laptop. These variables resulted in a Cronbach's Alpha coefficient of 0.60 . The summed total was then divided by seven (the total number of possible assets) to create a ratio.

Two interview question items were examined to measure primary sources of Indonesian mothers' stunting-related knowledge. One item addressed "from who" did mothers gain stunting-related knowledge and a second item addressed "from where" did mothers gain stunting-relating knowledge. Response categories for each question included hospital, the Internet, midwives, posyandu (integrated health post), and puskesmas (health center). A new variable was created for sources of stunting-related knowledge by combining these two items. For example, if a participant reported the Internet when asked "from who" and/or "from where", then they were coded as having used the Internet as a source of stunting-related knowledge. This was repeated for each of the sources of stunting-related knowledge.

Mothers also reported about their pregnancy status. By virtue of qualifying for this study, respondents were either pregnant or had recently given birth and had a child under two years of age. Lastly, participants were asked when they last received or accessed information about stunting. Categories included: first trimester, second trimester, or third trimester of pregnancy. This variable was used to estimate participants' initiative to actively seek out stunting-related information.

\subsection{Analysis}

Stata SE version 15.0 was used to conduct all analyses. Frequency statistics were calculated to summarize demographic variables and to identify sources of stunting-related knowledge. Logistic regression analysis was used to explore factors associated with accessing these sources of stunting-related knowledge, after con- 
trolling for age, education, wealth, pregnancy status, and the amount of time since mothers last sought nutrition information.

\section{Results}

The average age of participating mothers was just under 28 years of age, with roughly equal distributions of education (Table 1). Respondents reported an average of just under three home-based assets.

Posyandu is the Indonesian government's first line of attack in addressing undernutrition in rural settings. It was the most common source $(80.0 \%)$ for stunting-related knowledge (Table 2). Following posyandu, puskesmas were the second most common source $(31.7 \%)$ of stunting-relating knowledge among participants in this study. The Internet was the next most common source (16.9\%), followed by midwives (13.6\%) and hospitals (4.0\%).

Tables 3-5 present the results of adjusted regression analyses exploring factors associated with using the three most reported sources of stunting-related information. Factors associated with using posyandu for this information included higher education levels $(\mathrm{p}<0.01$ ), having already given birth to a child (compared to pregnant mothers) ( $\mathrm{p}<0.001$ ), and not utilizing puskesmas ( $\mathrm{p}<$ $0.001)$ or the Internet $(\mathrm{p}<0.001)$. For the model exploring puskesmas, significant variables included older age $(\mathrm{p}=0.10)$ and not accessing posyandu $(\mathrm{p}<$ $0.001)$ or the Internet $(\mathrm{p}<0.01)$. Lastly, using the Internet to access stunting-related information was associated with higher levels of education ( $\mathrm{p}<$ 0.001 ), having already given birth to a child ( $\mathrm{p}<0.05$ ), and not using posyandu ( $\mathrm{p}<0.001)$ or puskesmas $(\mathrm{p}<0.001)$ for such information.

Table 1. Sample characteristics, $n=745$.

\begin{tabular}{|c|c|c|c|}
\hline Variable & & $\%$ & $\mathrm{n}$ \\
\hline \multicolumn{4}{|c|}{ Highest level of education } \\
\hline & $\begin{array}{c}\text { Some elementary or elementary } \\
\text { graduate }\end{array}$ & 28.99 & 216 \\
\hline & $\begin{array}{l}\text { Some junior high or junior high } \\
\text { graduate }\end{array}$ & 24.83 & 185 \\
\hline & $\begin{array}{l}\text { Some high school or high school } \\
\text { graduate }\end{array}$ & 33.29 & 248 \\
\hline & Some college or college graduate & 12.89 & 96 \\
\hline \multicolumn{4}{|c|}{$\begin{array}{l}\text { When did the mother access } \\
\text { information about stunting? }\end{array}$} \\
\hline & $3^{\text {rd }}$ trimester & 31.41 & 234 \\
\hline & $2^{\text {nd }}$ trimester & 7.52 & 56 \\
\hline & $1^{\text {st }}$ trimester & 61.07 & 455 \\
\hline \multicolumn{4}{|c|}{ Mother status } \\
\hline & Pregnant & 30.20 & 225 \\
\hline
\end{tabular}




\begin{tabular}{lccc}
\hline & Child $<2$ & 69.80 & 520 \\
& & Mean & SD \\
Age & 27.92 & 6.91 \\
Assets & 2.88 & $1.44(0-7)$ \\
\hline
\end{tabular}

Table 2. Source of stunting information, $\mathrm{n}=745$.

\begin{tabular}{ccc}
\hline Source & $\%$ & $\mathrm{~N}$ \\
\hline Posyandu & 80.00 & 596 \\
Puskesmas & 31.68 & 236 \\
Internet & 16.91 & 126 \\
Midwife & 13.56 & 101 \\
Hospital & 4.03 & 30 \\
\hline
\end{tabular}

Note: Categories are not mutually exclusive.

Table 3. Factors associated with using posyandu to acquire stunting-related knowledge, $\mathrm{n}$ $=745$.

\begin{tabular}{ccccccc}
\hline Variable & OR & SE & Z & P & \multicolumn{2}{c}{$95 \%$ CI } \\
\hline Education & 0.731 & 0.079 & -2.88 & 0.004 & 0.591 & 0.904 \\
Age & 1.011 & 0.016 & 0.71 & 0.479 & 0.981 & 1.042 \\
When sought information & 0.888 & 0.103 & -1.02 & 0.308 & 0.707 & 1.116 \\
Assets & 0.496 & 0.256 & -1.36 & 0.174 & 0.181 & 1.364 \\
Pregnancy Status & 4.096 & 0.860 & 6.72 & 0.000 & 2.714 & 6.182 \\
Internet & 0.236 & 0.058 & -5.86 & 0.000 & 0.145 & 0.382 \\
Puskesmas & 0.307 & 0.066 & -5.53 & 0.000 & 0.202 & 0.466 \\
\hline
\end{tabular}

Table 4. Factors associated with using puskesmas to acquire stunting-related knowledge, $\mathrm{n}=745$.

\begin{tabular}{ccccccc}
\hline Variable & OR & SE & Z & P & \multicolumn{2}{c}{$95 \%$ CI } \\
\hline Education & 1.159 & 0.101 & 1.70 & 0.088 & 0.978 & 1.374 \\
Age & 1.031 & 0.012 & 2.58 & 0.010 & 1.007 & 1.056 \\
When sought information & 0.879 & 0.078 & -1.45 & 0.148 & 0.737 & 1.047 \\
Assets & 0.463 & 0.187 & -1.90 & 0.057 & 0.209 & 1.023 \\
Pregnancy Status & 0.884 & 0.162 & -0.67 & 0.503 & 0.617 & 1.267 \\
Internet & 0.481 & 0.118 & -2.97 & 0.003 & 0.297 & 0.779 \\
Posyandu & 0.311 & 0.066 & -5.51 & 0.000 & 0.205 & 0.471 \\
\hline
\end{tabular}


Table 5. Factors associated with using the Internet to acquire stunting-related knowledge, $\mathrm{n}=745$.

\begin{tabular}{ccccccc}
\hline Variable & OR & SE & Z & P & \multicolumn{2}{c}{$95 \%$ CI } \\
\hline Education & 1.522 & 0.167 & 3.82 & 0.000 & 1.227 & 1.888 \\
Age & 1.014 & 0.016 & 0.89 & 0.373 & 0.983 & 1.045 \\
When sought information & 1.206 & 0.143 & 1.57 & 0.116 & 0.955 & 1.522 \\
Assets & 1.348 & 0.689 & 0.58 & 0.559 & 0.495 & 3.673 \\
Pregnancy status & 1.641 & 0.399 & 2.04 & 0.042 & 1.018 & 2.645 \\
Posyandu & 0.241 & 0.059 & -5.76 & 0.000 & 0.149 & 0.391 \\
Puskesmas & 0.488 & 0.120 & -2.92 & 0.004 & 0.301 & 0.790 \\
\hline
\end{tabular}

\section{Discussion}

The purpose of this study was to identify Indonesian mothers' primary sources of stunting-related knowledge and to explore factors associated with accessing these sources. Posyandu is a local community health post and was the most common source of stunting-related information in this study. In the 1980s, the Indonesian government began establishing a posyandu network to provide community members monthly access to various health services and an entry point to larger national health systems [14]. Posyandu was designed as a community-based, integrated health post to provide basic maternal and child health services to families in rural settings such as family planning, nutrition, immunizations, and other local disease control efforts [15]. Posyandu was the result of merging resources and efforts from various government programs, with the intent that a single unified effort would increase the efficiency of services and improve a variety of important health outcomes [16]. Posyandu activities are largely in the care of community volunteers, called Cadres. The results of this study identifying posyandu as the most common source of stunting-related knowledge is somewhat expected given these community-based posts feature multiple locations per village [14], and are the entry point to the Indonesian health system [17]. The Indonesian government aims to reach and serve all rural communities through posyandu. Responses from mothers participating in this study provide evidence that the government's objective is very close to being accomplished. Promoting participation in posyandu should be an ongoing priority as mothers of young children that participate with high frequency may be more knowledgeable about nutritional topics [14]. Mothers with low education level were more likely to utilize posyandu. This supports research by Darmawati, which also showed lower educated mothers were more likely to access posyandu [18]. In that less educated mothers that already gave birth were using posyandu, it is essential that the information disseminated through the posyandu network is both accurate and tailored to the needs of participating mothers and their children.

Puskesmas, or public health centers, represent the second most common 
source of stunting-related knowledge among mothers is this study. By comparison, puskesmas are larger than posyandu, generally feature formally trained professionals, and offer more complete medical care. In many instances, puskesmas staff provides oversight to the posyandu and attending cadres [17]. Older mothers in this study were more likely to access puskesmas, which perhaps relates to their desire to seek out more comprehensive health care services. Facilities like puskesmas are intended to generate revenue to support staff salaries and supplement government subsidies [17]. For this reason, it is surprising that mothers in this study were more likely to access puskesmas if they reported fewer home-based assets. Future studies could explore this relationship in greater detail.

Many reports have documented Indonesia's growing number of Internet and social media users [19] [20]. Indonesia has the largest economy in Southeast Asia, with a GDP of US\$ 1 trillion in 2012. It is a G20 member, a stable democracy and the fourth most populated country in the world, with 251 million people, 50 percent of whom are below the age of 30. Indonesia's economy grew by an average of 5 percent annually from 2010-2017 [21]. As a result, Indonesia is rapidly moving into middle income status, with a growing middle class [22]. This rising income status will likely facilitate the country's transition to digital dependence in the immediate future. For health promotion purposes, this expands opportunities for servicing a diverse audience, including mothers in rural settings. In this study, educated mothers were more likely to access stunting-related knowledge on the Internet. It may seem odd that wealth was not significantly related, given the additional costs associated with accessing the Internet. Nevertheless, a recent report on the use of digital technologies for information seeking concluded that it is more a function of education level, not income or wealth [23]. It might be the case that more educated women feel comparatively comfortable accessing, evaluating the quality of, and interpreting stunting information from a digital source. Related to this, women that had already given birth also accessed information online. This may be the result of their experience and feeling more comfortable synthesizing the digital information with their lived experience. It may also be related to the potential convenience of accessing information online when compared to traveling with an infant or young child to posyandu or puskesmas.

\subsection{Limitations}

The findings from this study should be interpreted in the context of its limitations. The first limitation relates to assessing familial wealth using home-based assets, each of which was weighted equally. This could be misleading to equate a radio with an automobile, for example. Nevertheless, this measure provides at least an approximation to wealth and future studies with this population could improve wealth measures. Second, the findings from this study, while interesting, would be more impactful with the inclusion of comparisons of child out- 
comes. Unfortunately, actual measures of stunting were not collected. These data were collected for the purposes of informing a mass media campaign to prevent stunting, not to estimate stunting rates. In the event that post-campaign evaluations are possible, measures of stunting could enrich the interpretation of the findings.

\subsection{Conclusion}

The results from this study support a comprehensive, multi-platform approach to addressing the complex issue of childhood stunting in Indonesia. The major sources of stunting-related knowledge in this study were each significantly associated with not accessing the other sources. It appears, then, that each source is servicing a unique and distinct segment of the population as it relates to disseminating stunting-related knowledge. Indonesian professionals wishing to influence stunting knowledge may benefit from utilizing a multi-faceted approach, taking advantage of the convenience of the posyandu, the credibility of the puskesmas and the low-cost, wide distribution to rural areas afforded by the Internet. Relying too much on any single source may result in missed opportunities for influencing mothers. Future studies may consider mothers' specific preferences relating to each of these sources and how they access this information, and the relative impact on actual stunting-related knowledge.

\section{Declarations}

\subsection{Ethics Approval and Consent to Participate}

The Universitas Indonesia human subjects review board approved this study's methods and procedures.

\subsection{Consent for Publication}

Prior to participating, respondents provided consent to participate in the study and to for the results to be published.

\subsection{Availability of Data and Materials}

The data that support the findings of this study are available from Ahmad Syafiq but restrictions apply to the availability of these data, which were used under license for the current study, and so are not publicly available. Data are however available from the authors upon reasonable request and with permission of IMA World Health.

\subsection{Conflicts of Interest}

The authors declare no conflicts of interest regarding the publication of this paper.

\subsection{Funding}

This research was supported by funds from IMA World Health. 


\subsection{Author's Contributions}

JW, BC, CH ST ML AS were major contributors in writing the manuscript. JW analyzed and interpreted the data. $\mathrm{CB}$ and $\mathrm{IH}$ assisted in data interpretation and the study's background. AS oversaw data collection.

\section{References}

[1] Grantham-McGregor, S. (2002) Linear Growth Retardation and Cognition. Lancet, 359, 542. https://doi.org/10.1016/S0140-6736(02)07719-X

[2] De Onis, M., Blössner, M. and Borghi, E. (2012) Prevalence and Trends of Stunting among Pre-School Children, 1990-2020. Public Health Nutrition, 15, 142-148. https://doi.org/10.1017/S1368980011001315

[3] Atmarita, T. (2008) A Summary of the Current Nutrition Situation in Indonesia. Capacity and Leadership Development in Nutritional Sciences, Seoul, Korea.

[4] World Health Organization (2017) Stunted Growth and Development. Secondary Stunted Growth and Development 2017.

http://www.who.int/nutrition/childhood_stunting_framework_leaflet_en.pdf?ua=1

[5] Wamani, H., Åstrøm, A.N., Peterson, S., Tylleskär, T. and Tumwine, J.K. (2005) Infant and Young Child Feeding in Western Uganda: Knowledge, Practices and Socio-Economic Correlates. Journal of Tropical Pediatrics, 51, 356-361. https://doi.org/10.1093/tropej/fmi048

[6] Burchi, F. (2010) Child Nutrition in Mozambique in 2003: The Role of Mother's Schooling and Nutrition Knowledge. Economics \& Human Biology, 8, 331-345. https://doi.org/10.1016/j.ehb.2010.05.010

[7] Christiaensen, L. and Alderman, H. (2004) Child malnutrition in Ethiopia: Can Maternal Knowledge Augment the Role of Income? Economic Development and Cultural Change, 52, 287-312. https://doi.org/10.1086/380822

[8] Saaka, M. (2014) Relationship between Mothers' Nutritional Knowledge in Childcare Practices and the Growth of Children Living in Impoverished Rural Communities. Journal of Health, Population, and Nutrition, 32, 237.

[9] Carruth, B.R. and Skinner, J.D. (2001) Mothers' Sources of Information about Feeding Their Children Ages 2 Months to 54 Months. Journal of Nutrition Education, 33, 143-147. https://doi.org/10.1016/S1499-4046(06)60183-8

[10] Chen, P.G., Johnson, L.W. and Rosenthal, M.S. (2012) Sources of Education about Breastfeeding and Breast Pump Use: What Effect Do They Have on Breastfeeding Duration? An Analysis of the Infant Feeding Practices Survey II. Maternal and Child Health Journal, 16, 1421-1430. https://doi.org/10.1007/s10995-011-0908-4

[11] Thackeray, R., Crookston, B.T. and West, J.H. (2013) Correlates of Health-Related Social Media Use among Adults. Journal of Medical Internet Research, 15, e21. https://doi.org/10.2196/jmir.2297

[12] Saleh, A.G. and Lasisi, F.I. (2011) Information Needs and Information Seeking Behavior of Rural Women in Borno State, Nigeria. Library Philosophy and Practice, 625.

[13] Bennett, S., Woods, T., Liyanage, W.M. and Smith, D.L. (1991) A Simplified General Method for Cluster-Sample Surveys of Health in Developing Countries. World Health Statistics Quarterly, 44, 98-106.

[14] Anwar, F., Khomsan, A., Sukandar, D., Riyadi, H. and Mudjajanto, E.S. (2010) High Participation in the Posyandu Nutrition Program Improved Children Nutritional 
Status. Nutrition Research and Practice, 4, 208-214.

https://doi.org/10.4162/nrp.2010.4.3.208

[15] Leimena, S. (1989) Posyandu: A Community Based Vehicle to Improve Child Survival and Development. Asia Pacific Journal of Public Health, 3, 264-267. https://doi.org/10.1177/101053958900300402

[16] Nazri, C., et al. (2016) Factors Influencing Mother's Participation in Posyandu for Improving Nutritional Status of Children Under-Five in Aceh Utara District, Aceh Province, Indonesia. BMC Public Health, 16, 69.

[17] Council, N.R. (2013) Reducing Maternal and Neonatal Mortality in Indonesia: Saving Lives, Saving the Future. National Academies Press, Washington DC.

[18] Darmawati, I. (2001) Performance of Posyandu in Pandeglang. Department of Community Nutrition and Family Resources, Faculty of Agriculture, Bogor.

[19] Lim, M. (2013) Many Clicks But Little Sticks: Social Media Activism in Indonesia. Journal of Contemporary Asia, 43, 636-657. https://doi.org/10.1080/00472336.2013.769386

[20] Kristiansen, S., Wahid, F. and Furuholt, B. (2006) Investing in Knowledge? Information Asymmetry and Indonesian Schooling. The International Information \& Library Review, 38, 192-204. https://doi.org/10.1080/10572317.2006.10762722

[21] Trading Economics (2017) Indonesia GDP Annual Growth Rate. Secondary Indonesia GDP Annual Growth Rate.

https://tradingeconomics.com/indonesia/gdp-growth-annual

[22] Rastogi, V., Tamboto, E., Tong, D. and Sinburimsit, T. (2013) Indonesia's Rising Middle-Class and Affluent Consumers: Asia's Next Big Opportunity.

[23] Dutta, R. (2009) Information Needs and Information-Seeking Behavior in Developing Countries: A Review of the Research. The International Information \& Library Review, 41, 44-51. https://doi.org/10.1080/10572317.2009.10762796 